\title{
Effects of Heat Treatments on the Corrosion Rates and Hardness Properties of Welded Low Carbon Steel in Sodium Hydroxide Medium.
}

Olabisi, O.I. and Olorumnishola, A.A.G.

Department of Mechanical Engineering,The Federal Polytechnic,Ado-Ekiti,Nigeria.

In manufacturing and allied industries, there are occasions where low carbon steel welds do come in contact with corrosion media. The harmful effect of corrosion on the material could not be left un-checked because of the contribution of the agro-allied industries to boost her economy. Therefore, there is need for proper understanding of locally available material like low carbon steel's behavior in different corrosion environment to determine the suitability of such material for manufacturing and fabrication. The chemical component of the commercially obtained low carbon steel was determined using x-ray spectrometer to ascertain its class. The arc and gas welded low carbon steel samples were subjected to different heat treatment methods such as annealing, normalizing, quenching and tempering. The coupons/low carbon steel samples in its original form (i.e. as-received/control) and heat treated formats were prepared and exposed to sodium hydroxide $(\mathrm{NaOH})$ solution using ASTM guidelines. Weight loss method was used to determine the corrosion rate of the coupons in the tested medium. It was deduced from the study that gas welding aids reduction in the corrosion rate of the locally available low carbon steel in concentrated $\mathrm{NaOH}$ solution than arc welding. Normalizing, quenching and annealing were found to be effective heat treatment methods that might be useful in improving the corrosion behaviour of gas welded low carbon steel in $\mathrm{NaOH}$ processing plants and equipment.

Keywords:Sodium hydroxide, low carbon steel, annealing, normalizing, quenching and tempering.

\section{Introduction}

Welding often done by melting the work pieces and filler material is added to form a pool of molten material that cools to become a strong joint, with the pressure, sometimes used in conjuction with heat, or by itself, to produce the weld. The history of joining metals goes back several millennia with the earliest examples of welding from the Bronze Age and Iron Age in Europe and the Middle East (Waterfield, 1986). The common types of welding are such as oxy fuel gas welding, arc welding and resistance welding. For arc welding, there are plasma arc welding and carbon arc welding. Gas welding include Tungsten Inert Gas (TIG) welding and Metal Inert Gas (MIG) welding. Resistance welding has spot and seamwelding (Saufley, 2001). Welding technology is a high productive and practical joining method used in modern manufacturing industry such as shipbuilding, automobile, bridge etc. It is also a type of fabrication or sculptural process that joins materials, usually metals or thermoplastics by causing coalescence (Jiangchao et al., 2011)

The modernization of this era expands the demands and applications of carbon steel especially in construction industry and the naval structure builder (Bodunde, 2006). A lot of mega steel structure platforms have been designed and constructed to fulfill the exploitation 
of civilization. Most of these structures are fabricated by technique of welding. However, steel welds are more vulnerable to corrosion and crack than the corresponding base plates, the welded zones represent potential weak links which may limit or impair performance. Moreover, the corrosion in seawater is reflected by the fact that most of the common structural metals and alloys are attacked by this liquid or its surrounding environments. Thus, improvements in welded properties are critical to increase the reliability of high-performance structures utilizing welded carbon materials. A fundamental study of the properties of the welded zone of carbon steel was carried out by means of gas and electric arc welding. With the electrochemical measurement, the corrosion resistance for each welded area was determined (Saleh et al., 2005).

Corrosion has been a recognized and an inevitable process of material degradation through chemical and electromechanical reaction and microbiological metabolism (Obikwelu, 2008). This phenomenon is also known to be very costly and has a major impact on the economies of industrial nations, because it can lead to failures in plants, infrastructures and machines (Shuaib-Babata, 2008). Corrosion is degradation of materials properties due to interactions with their environments, and corrosion of most metals is inevitable (Barbara and Robert, 2006). While primarily associated with metallic materials, all material types are susceptible to degradation. Corrosion can also be defined as the breaking down of essential properties in materials due to chemical reactions with its surroundings. According to Umoru (2001), corrosion is the destruction of metals as a result of their chemical and electrochemical reactions with its environment. Corrosion is the deterioration of intrinsic properties in a material due to reactions with its environment. A typical example is weakening of iron due to oxidation of iron atom, this called RUST. Rust affects material and produces oxide(s) or salt(s) of the original metal. Also, it includes discoloration and weakening of polymers by sun's ultraviolet light and dissolution of ceramic materials.Most structural alloys corrode merely from exposure to moisture in air, but the process can be strongly affected by exposure to certain substance e.g. acids etc. Corrosion can be concentrated locally to form a pit/crack or it can be extended across a wide area to produce a general deterioration

Hence, this paper intends to study the corrosion behavior of welded low carbon steel and to evaluate the extent of its damages in sea water and sodium hydroxide $(\mathrm{NaOH})$ environments. The results of this study would be of great benefit to the local fabricators.

\section{Experimental Procedures}

\section{Equipment and Materials}

The equipment and apparatus used include sheet metal cutting machine, drilling machine, drill bits, measuring cylinders, electric weighing machine, hot blower machine, beakers, electric furnace,computerized universal tensile testing machine (UTM) and Rockwell hardness testing machine. The materials used were locally available low carbon steel sheet metal (of gauge length $0.7 \mathrm{~mm}$ ), concentrated sodium hydroxide $(\mathrm{NaOH})$ solution, lagging cover and thread for tagging the coupons. The sheet metal was cut into two segments i.e. coupons for corrosion test and specimens for hardness tests. The dimensions of coupons for corrosion and specimens for hardness tests were $20 \mathrm{~mm}$ by $15 \mathrm{~mm}$ by $0.7 \mathrm{~mm}$ and $50 \mathrm{~mm}$ by $40 \mathrm{~mm}$ by $0.7 \mathrm{~mm}$ respectively. The coupons were drilled with $0.5 \mathrm{~mm}$ drill bit in order to give room for tagging with thread for easy identification. The chemical analysis of the sheet metal was carried out to show the composition of the steel and the result is presented in Table 1. 
Table 1: Chemical Composition of the As-Received Untreated (i.e control) Low Carbon Steel

\begin{tabular}{|l|l|l|l|l|l|l|l|l|l|}
\hline Element & $\mathrm{C}$ & $\mathrm{Sr}$ & $\mathrm{Mn}$ & $\mathrm{P}$ & $\mathrm{S}$ & $\mathrm{Cr}$ & $\mathrm{Ni}$ & $\mathrm{Mo}$ & $\mathrm{Al}$ \\
\hline$\%$ & 0.032 & $<0.0001$ & 0.306 & 0.012 & 0.022 & 0.016 & 0.023 & $<0.0001$ & 0.019 \\
\hline Element & $\mathrm{Cu}$ & $\mathrm{Co}$ & $\mathrm{Ti}$ & $\mathrm{Nb}$ & $\mathrm{V}$ & $\mathrm{W}$ & $\mathrm{Pb}$ & $\mathrm{B}$ & $\mathrm{Sn}$ \\
\hline$\%$ & 0.015 & 0.0003 & 0.0013 & 0.0095 & 0.0034 & $<0.0001$ & 0.0047 & 0.0005 & 0.0006 \\
\hline Element & $\mathrm{Zn}$ & $\mathrm{As}$ & $\mathrm{Bi}$ & $\mathrm{Ca}$ & $\mathrm{Ce}$ & $\mathrm{Zr}$ & $\mathrm{La}$ & $\mathrm{Fe}$ & \\
\hline$\%$ & 0.0009 & $<0.0001$ & 0.0011 & 0.0003 & 0.0090 & 0.0034 & 0.0005 & 99.5 & \\
\hline
\end{tabular}

The method of corrosion test employed is laboratory test, which involves full immersion of the specimens and coupons weight loss determination in line with ASTM guideline (ASTM, 1994).

\section{Heat Treatment Methods}

The welded low carbon steel coupons and specimens were subjected to various heat treatment methods. The heat treatment methods considered include the following:

Annealing: The specimens/coupons were charged into the furnace, and then heated to a temperature $930^{\circ} \mathrm{C}$, and soaked for thirty minutes. During the soaking period, the furnace was then switched off and the specimens were allowed to cool slowly in the furnace.

Normalizing:The specimens were charged into the furnace, heated to a temperature $930^{\circ} \mathrm{C}$, and soaked for 30minutes. The furnace was switched off after attaining the time and the specimens were brought out of the furnace and allowed to cool in still air.

Quenching: The specimens were also charged into the furnace, and then heated to a temperature $930^{\circ} \mathrm{C}$, and soaked for 30 minutes. The furnace was switched off after attaining the time and then the specimen were brought out of the furnace and quenched rapidly in distilled water.

Tempering:Some of the already quenched test specimens were re-heated to $450^{\circ} \mathrm{C}$, the temperature at which it was held at $450^{\circ} \mathrm{C}$ for about 30 minutes. The specimens were allowed to cool slowly in still air.

\section{Welding Technique}

The welding techniques employed in this work were electric arc and gas welding.

\section{Pre-Immersion Surface Preparation}

The pre-immersion surface preparation of the coupons/specimens was carried out to achieve uniformity on the surfaces of the test metals. The process was carried out using ASTM standard G31. The specimens were shook rigorously in benzene to remove organic oil and any other workshop impurities. The specimens were then shook rigorously in ethanol to remove abraded particles and hot dried. The initial weights of the coupons/specimens were determined immediately with electric weighing balance.

\section{Immersion}

The already weighed heat treated welded coupons/specimens and as-received (i.e. control) coupons/specimens were immersed after surface preparation into sodium hydroxide solution by hanging them with inelastic thread attached to the lids of beakers that housed the media for a period of 24 hours to 720 hours. All test media were under closed conditions. 


\section{Post-Immersion Surface Preparation}

After immersion, the corrosion products were cleaned using chemical method. The solution in accordance with ASTM (2004) comprises of $500 \mathrm{ml} \mathrm{HCl}$ and $3.5 \mathrm{~g}$ hexanemethyl dissolved in $500 \mathrm{ml}$ distilled water to $1000 \mathrm{ml}$ solution. The specimens/coupons were shook rigorously in the solution for ten minutes. The cleaned specimens were rinsed in water to remove excess acid, dried in ethanol, hot air and kept in electric weighing balance for final mass $\left(\mathrm{M}_{2}\right)$.

\section{Assessment of Corrosion Damages}

The weight loss method was employed to assess the corrosion damages since the surface of the corroded specimens appear to large extent uniform. Weight loss is the measure of difference between the original mass of the specimen before immersion $\left(\mathrm{M}_{1}\right)$ and the mass of the same specimen after immersion and cleaning $\left(\mathrm{M}_{2}\right)$. The corrosion rate by weight loss wethod is calculated in mils per year (ASTM, 1985) using the formula given by:

$$
\text { Corrosion Rate }=\frac{K W}{D A T} \text { mpy }
$$

Where $\mathrm{K}=534$ (corrosion rate constant), $\mathrm{W}=$ weight loss (gram), $\mathrm{D}=$ density of the material $=7.86 \mathrm{~g} / \mathrm{cm}^{3}$ for mild steel, $\mathrm{A}=$ total area of exposure $=19 \mathrm{~cm}^{2}, \mathrm{~T}=$ exposure time in hours, mpy $=$ mils per year (corrosion rate unit)

\section{Results and Discussion}

The spectrometer test of the steel was shown in Table 1 which confirmed that the type of steel used for this work is a low carbon steel. The corrosion rates of the untreated (i.e control) and various heat treated specimens for both arc and gas welding in sodium hydroxide $(\mathrm{NaOH})$ solution were shown in Figures $1-5$.

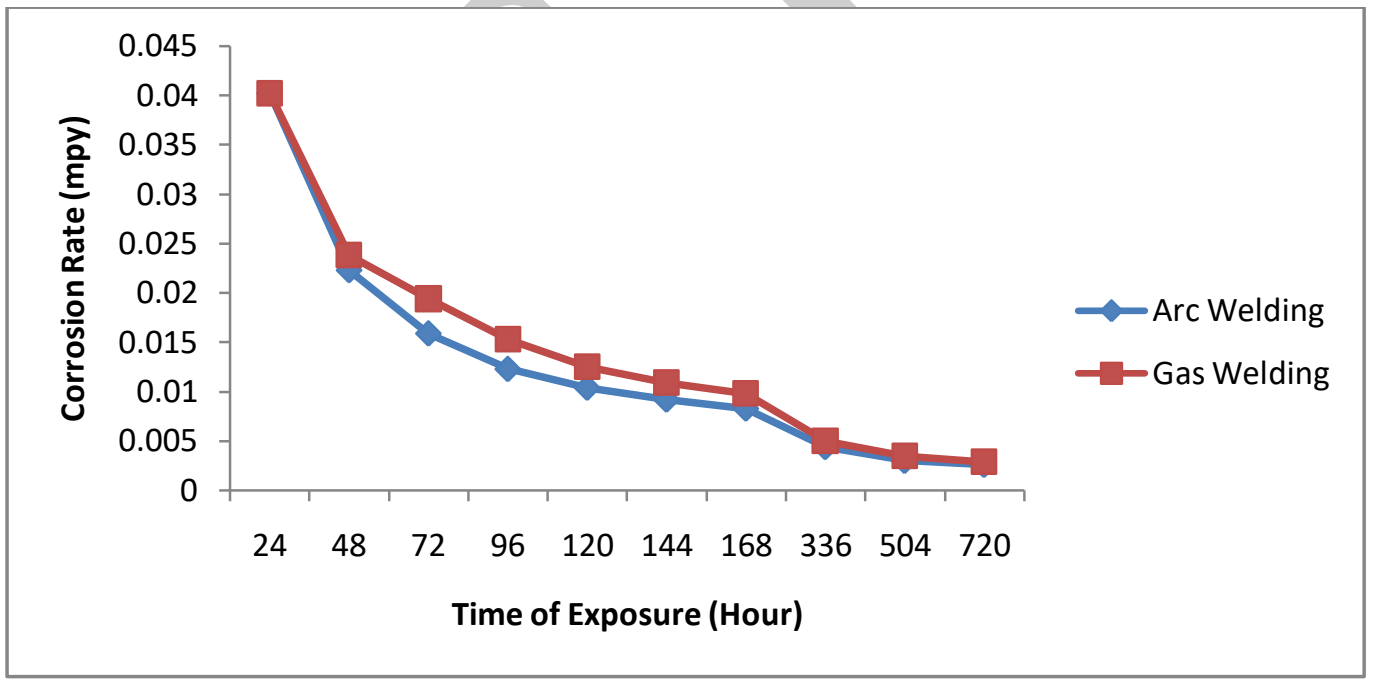

Fig. 1: Corrosion Rate of the Untreated (Control) Specimens in $\mathrm{NaOH}$ 


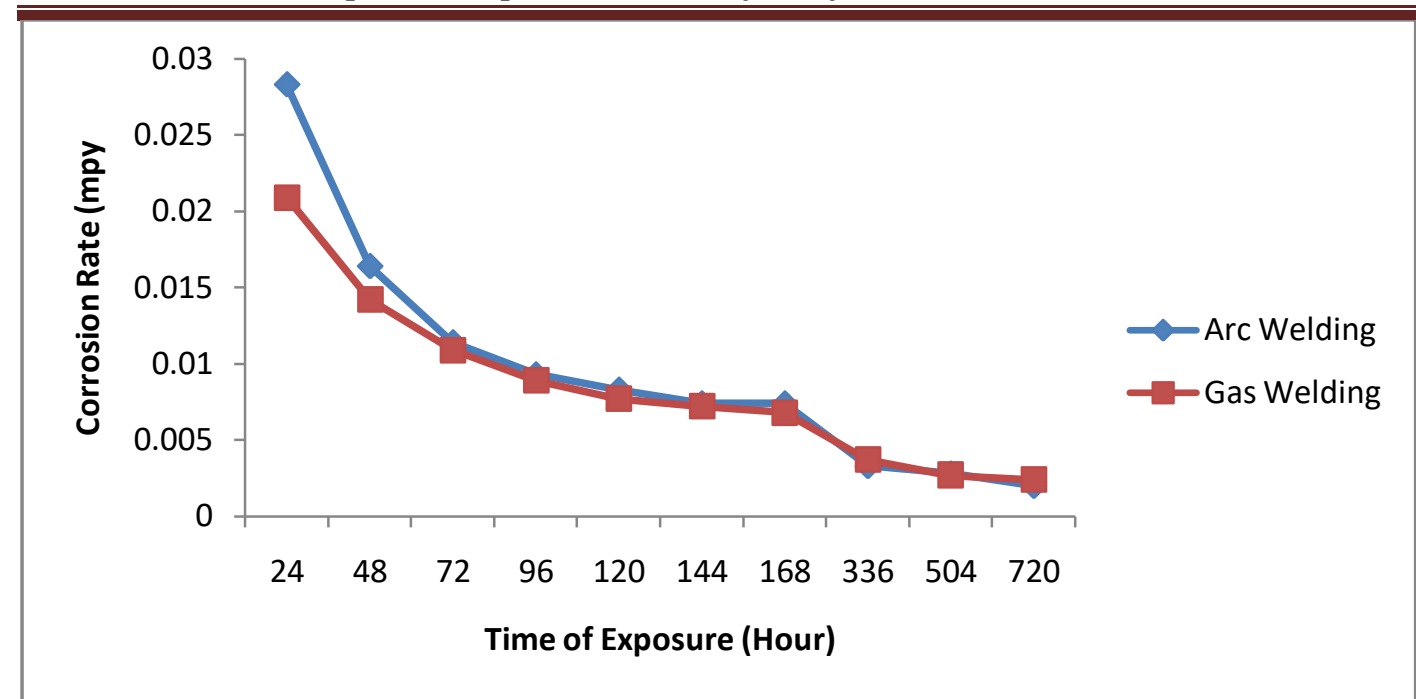

Fig. 2: Corrosion Rate of the Normalized Specimens in $\mathrm{NaOH}$

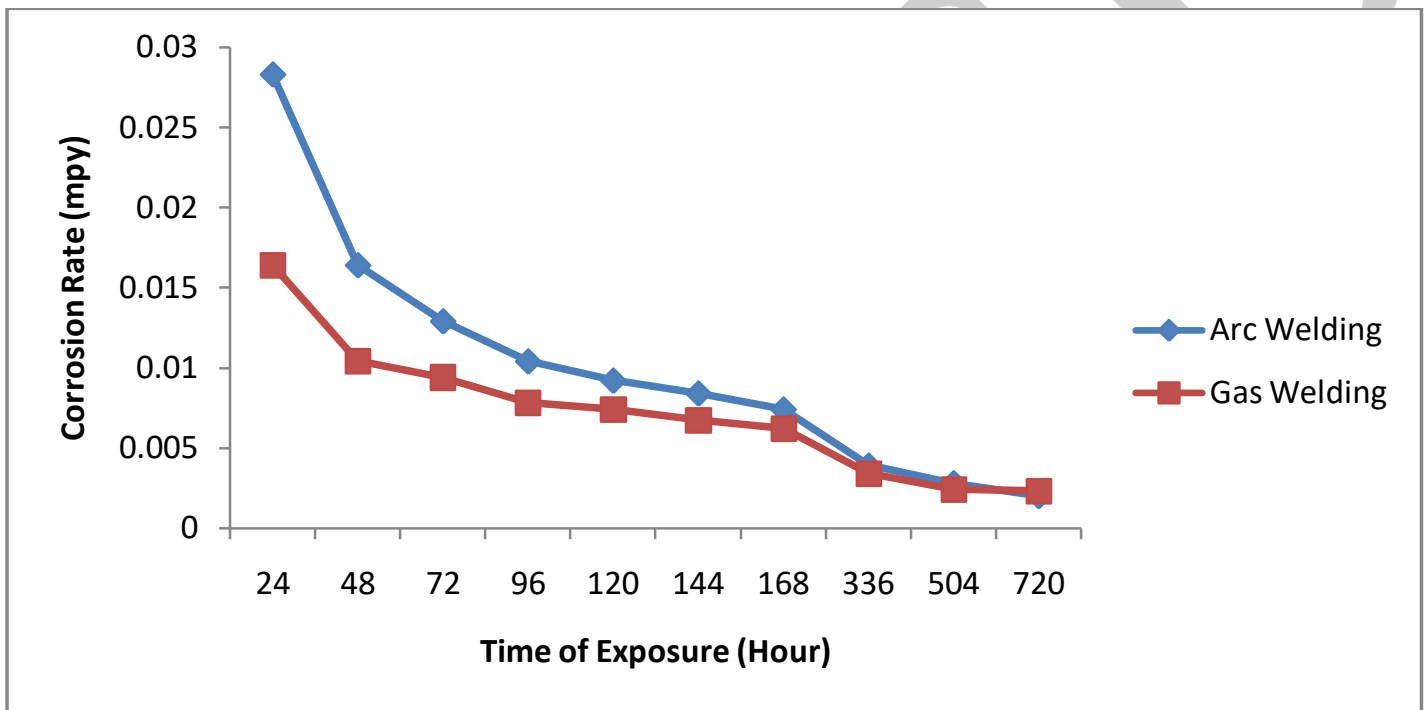

Fig. 3: Corrosion Rates of the Quenched Specimens in $\mathrm{NaOH}$

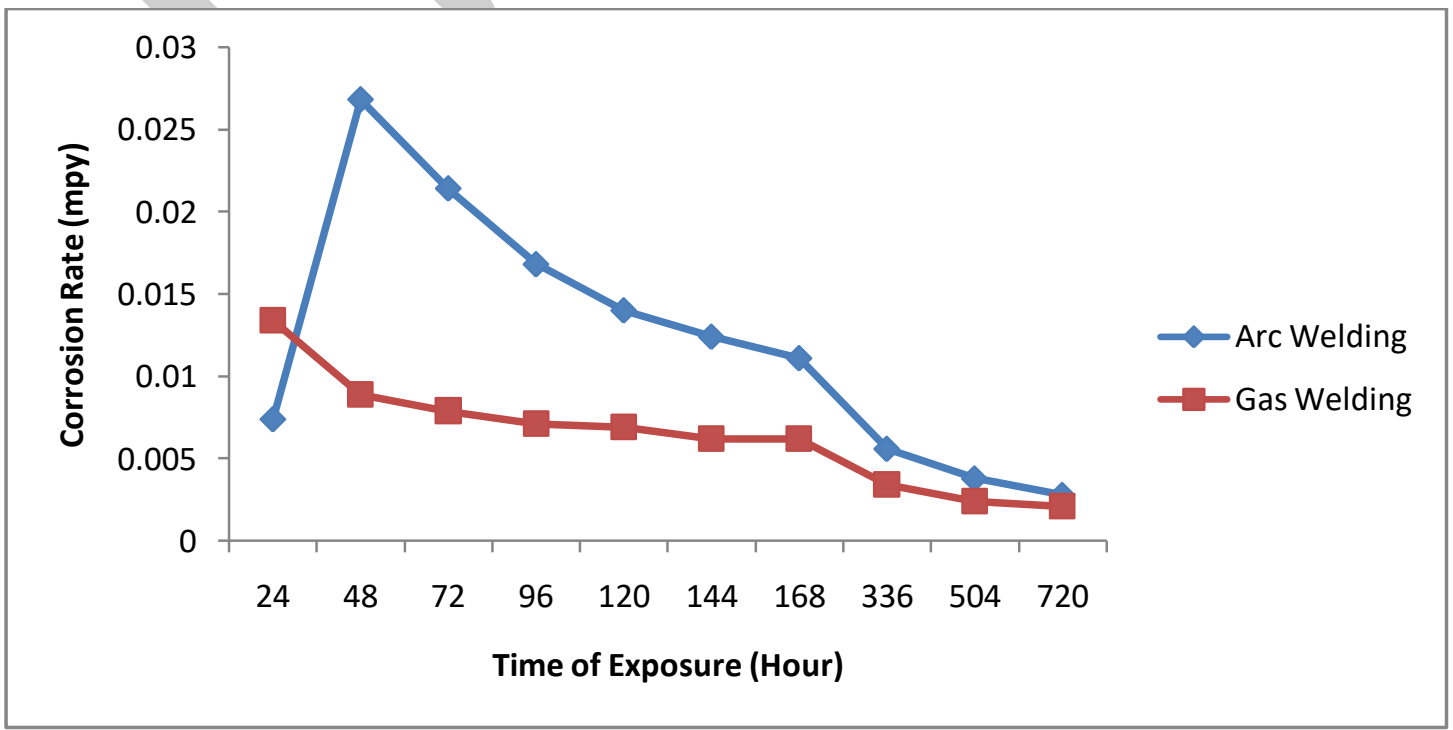

Fig. 4: Corrosion Rates of the Annealed Specimens in $\mathrm{NaOH}$ 


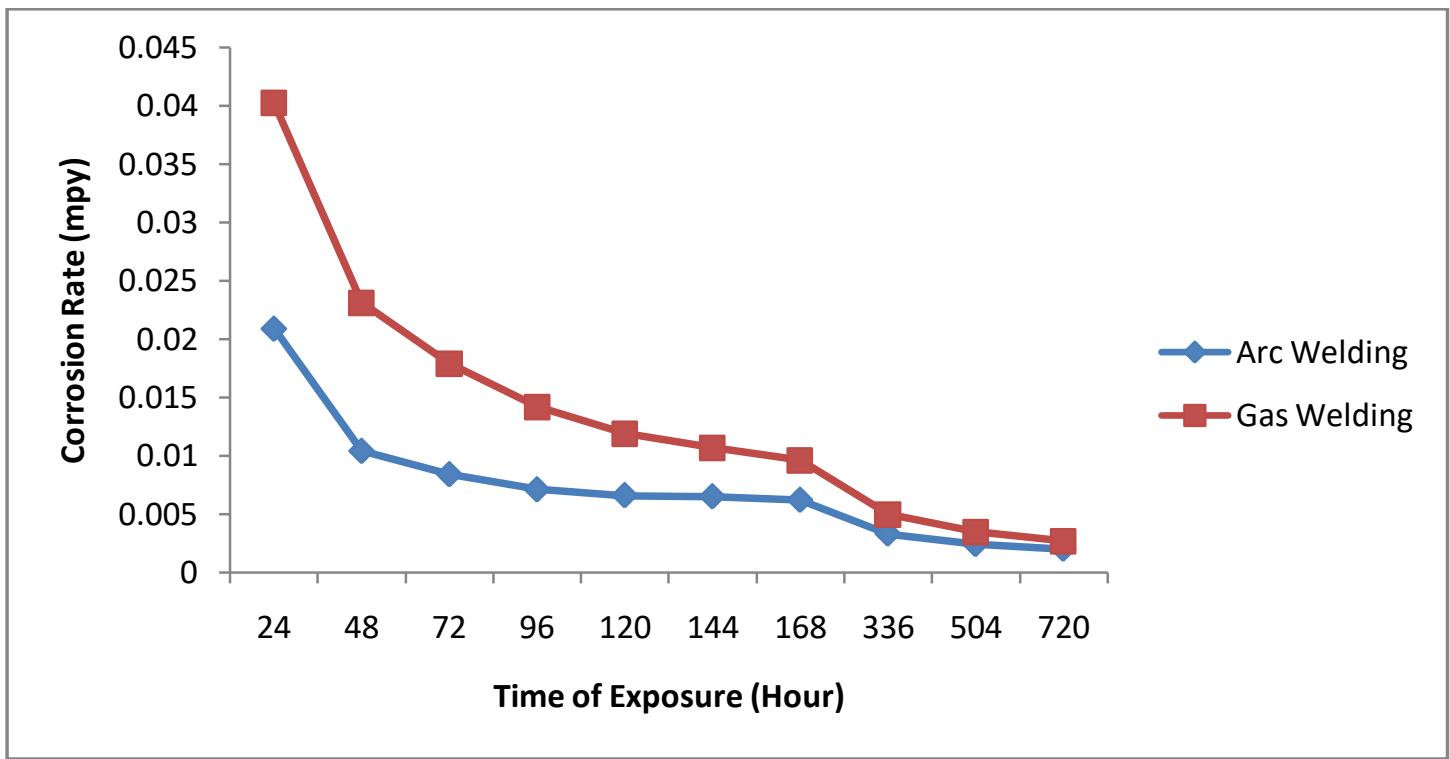

Fig. 5: Corrosion Rates of the Tempered Specimens in $\mathrm{NaOH}$

The corrosion rates of all the specimens (i.e both untreated and heat treated) were very high at the initial stages which thereafter reduces with time. According to Shuaib-Babata and Momoh (2012), the high initial corrosion rate might be due to the fresh activated surface of the welded joint and high oxygen content of the solution. Also, the reduction might have resulted from the formation of a product layer around the welded joint which have shielded the surface from furthet corrosion.

Fig. 6 revealed the average corrosion rates of the welded low carbon steel exposed for 720 hours in $\mathrm{NaOH}$ solution.

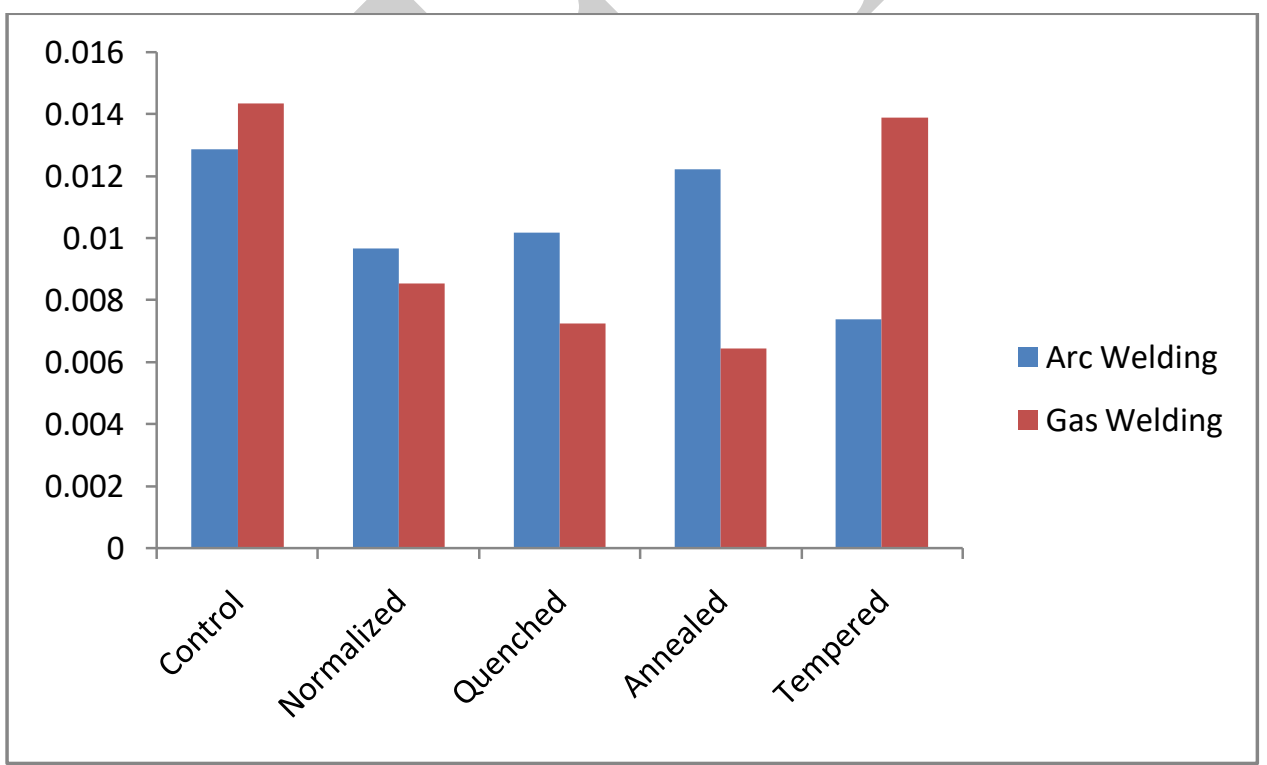

Fig. 6: Average Corrosion Rates of the Low Carbon Steel Exposed for 720 hours

The figure shows that the arc welded low carbon steel corroded more than those gas welded in the case of normalized, quenched and annealed specimens. The average corrosion rates of the heat treated gas welded low carbon steel were generally low and uniform except in the case of tempered specimens. In Fig. 4, the sudden increment in the corrosion rate of annealed 
arc welded steel between 24 and 48 hours of exposure might be attributed to the corrosion products which fell off from the surfaces of the steel which expose it to further corrosion.

Table 2 and 3 revealed the effect of corrosivity on the hardness properties of the welded low carbon steel.

Table 2: Hardness Properties of Arc Welded Specimens in $\mathrm{NaOH}$ Medium

\begin{tabular}{|c|c|c|c|c|c|}
\hline Treatment & $\begin{array}{c}\text { Ball } \\
\text { Diameter } \\
(\mathbf{m m})\end{array}$ & $\begin{array}{c}\text { Indentation } \\
\text { Diameter(mm) }\end{array}$ & $\begin{array}{c}\text { Brinell } \\
\text { Hardness } \\
\left(\mathbf{k g} / \mathbf{m}^{2}\right) \\
\end{array}$ & $\begin{array}{c}\text { Force@ } \\
\text { Peak } \\
(\text { kgf })\end{array}$ & $\begin{array}{r}\text { Def@ } \\
\text { Peak } \\
(\mathrm{mm})\end{array}$ \\
\hline Control & 10 & 3.84 & 83116.270 & 1000.953 & 1.859 \\
\hline Quench & 10 & 3.43 & 105094.465 & 1001.463 & 1.626 \\
\hline Tempering & 10 & 4.25 & 67247.533 & 1001.463 & 1.751 \\
\hline Annealing & 10 & 4.54 & 58450.161 & 1000.749 & 1.979 \\
\hline Normalizing & 10 & 4.31 & 65284.073 & 1001.361 & 2.116 \\
\hline
\end{tabular}

Table 3: Hardness Properties of Gas Welded Specimens in $\mathrm{NaOH}$ Medium

\begin{tabular}{|l|c|c|c|c|c|}
\hline Treatment & $\begin{array}{c}\text { Ball } \\
\text { Diameter }\end{array}$ & Indentation & $\begin{array}{c}\text { Brinell } \\
\text { Hardness } \\
\left(\mathbf{k g} / \mathbf{m}^{\mathbf{2}}\right)\end{array}$ & $\begin{array}{c}\text { Force @ } \\
\text { Peak } \\
\mathbf{( k g )}\end{array}$ & $\begin{array}{c}\text { Def @ } \\
\text { Peak } \\
\mathbf{( m m})\end{array}$ \\
\hline Control & 10 & 3.38 & 108228.545 & 1000.546 & 1.978 \\
\hline Quench & 10 & 3.04 & 134860.089 & 1002.585 & 1.04 \\
\hline Tempering & 10 & 3.53 & 98913.51 & 1000.24 & 1.264 \\
\hline Annealing & 10 & 3.93 & 79212.584 & 1001.157 & 1.107 \\
\hline Normalizing & 10 & 4.08 & 73296.381 & 1001.871 & 1.504 \\
\hline
\end{tabular}

The corrosivity of the steel significantly reduced the hardness of the heat treated steel in both welding methods except the quenched specimens. The quenched specimens in both arc and gas welding had higher Brinell Hardness of 105094.465 and $134860.089 \mathrm{~kg} / \mathrm{m}^{2}$ respectively than all other heat treated specimens.

\section{Conclusion}

In conclusion, the following facts are derived from the study:

- Normalizing, quenching and annealing were found to be effective heat treatment methods that might be useful in curbing the corrosivity of gas welded low carbon steel joints in sodium hydroxide processing plants and equipment.

- It can also be concluded from the study that gas welding aids reduction of corrosion rate in $\mathrm{NaOH}$ solution than arc welding.

- Quenching increased the hardness of heat treated steel samples than all other heat treatment methods.

\section{Recommendations}

The paper recommend normalizing, annealing and quenching as the most effective methods of heat treatment for curbing corrosion rate of gas welded low carbon steel in concentrated 
$\mathrm{NaOH}$ solution. Hence, gas welding should be adopted as a fabrication method of equipment and devices that house concentrated sodium hydroxide solution.

\section{References}

American Standard of Testing and Materials (2004). Standard Practice for Laboratory Immersion Corrosion Testing of Metals, Designation G1-30, ASTM International, pg. $1-8$.

Barbara, A.S. and Robert, G.K. (2006). Investigation of Low Carbon in Corrosion Media, The Electrochemical Society Interface, Vol.6, No.3, pg 567-575

Bodunde, M.A. (2006). Integrity assessment of locally produced low carbon steel for oil and gas transportation. Ph.D. Thesis, Federal University of Technology, Akure.

Jiangchao Wang, Ninshu Ma, H. Murakawa and Shijian Yuan (2011). Prediction and measurement of welding distortion of a spherical structure assembled from multi thin plates; Materials \& Design; pg 4728-4737

Obikwelu, D.O.N. (2008). Metallurgical Review of the Modern Trends in Materials Corrosion and Prevention. Journal of Research in Engineering, Science and Technology, Vol. 3, No. 2, pg. 121-127.

Saleh, A., Al-Fozan and Anees M.U. (2005). "Effect of Sea Water level on Corrosion Behaviour of Different Alloys." Desalination. Vol.3 pp. 61-67.

Saufley Field (2001). Introduction to Welding, pg 3

Shuaib-Babata, Y.L. (2008). Significance of Corrosion: A Case Study of Nigeria.Journal of Engineering and Science Technology, Vol. 3, No. 2, pg. 52-55.

Shuaib-Babata, Y.L. and Momoh, J.J. (2012). Corrosion behaviour of Mild Steel in Different Formats in Orange and Pineaple Juice Media. Journal of Engineering and Earth Sciences, Volume 6, No 2, pg 63-

Umoru (2001). Corrosion of mild steel in some environment. Corrosion science (NCA), pg $61-65$

Waterfield, R. (1986). Herodotus. The Histories; Publisher: Oxford University Press 